\title{
Protein arginine methyltransferase 1 promotes epithelial-mesenchymal transition via TGF- $\beta 1 /$ Smad pathway in hepatic carcinoma cells
}

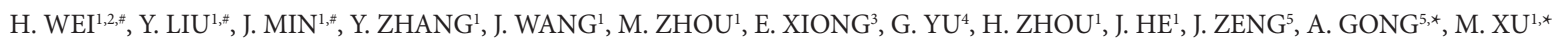

${ }^{1}$ Department of Gastroenterology, Affiliated Hospital of Jiangsu University, Jiangsu University, Zhenjiang, China; ${ }^{2}$ Department of Gastroenterology, Xuzhou Cancer Hospital, Xuzhou, China; ${ }^{3}$ Department of Immunology, School of Basic Medical Sciences, Fudan University, Shanghai, China; ${ }^{4}$ Department of Oncology, Changzheng Hospital, Shanghai, China; ${ }^{5}$ Department of Cell Biology, School of Medicine, Jiangsu University, Zhenjiang, China

*Correspondence: ahg5@mail.ujs.edu.cn; peterxu1974@163.com

${ }^{*}$ Contributed equally to this work.

Received December 26, 2018 / Accepted April 29, 2019

\begin{abstract}
Protein arginine methyltransferase 1 (PRMT1) is dysregulated in a number of human cancers. Herein, we report that PRMT1 expression is directly associated with epithelial-mesenchymal transition (EMT) in hepatic carcinoma cells. Firstly, we find that PRMT1 expression is higher in hepatic carcinoma tissues than that in normal liver tissues at both mRNA and protein levels, and higher expression of PRMT1 correlates with poor survival in liver tumors. The data in vitro reveals that PRMT1 knockdown inhibits the abilities of proliferation, migration and invasion, while PRMT1 overexpression promotes the above behaviors in hepatic carcinoma cells. Further studies indicate that PRMT1 knockdown remarkably decreases the expression of mesenchymal markers including Vimentin, Snail and N-cadherin, and upregulates expression of epithelial markers E-cadherin. Conversely, PRMT1 overexpression results in the opposite effects. Additionally, we identified that PRMT1 knockdown resulted in downregulation of TGF- $\beta 1$, p-Smad 2 and p-Smad3, while PRMT1 overexpression activated TGF- $\beta 1$, p-Smad2 and p-Smad3. These findings suggest that PRMT1 promotes EMT in hepatic carcinoma cells probably via TGF- $\beta 1 /$ Smad pathway, and might represent a novel anti-liver cancer strategy.
\end{abstract}

Key words: PRMT1, EMT, hepatic carcinoma cell, TGF- $\beta 1 /$ Smad, proliferation

Liver cancer is ranked as the fifth most frequently diagnosed cancer worldwide and the third most frequent cause of cancer-related death [1-3]. An estimated 782,500 new liver cancer cases and 745,500 deaths occurred worldwide during 2012, with China alone accounting for about $50 \%$ of the total number of cases and deaths. The most frequently occurring primary liver cancer (70-90\%) worldwide is hepatocellular carcinoma (HCC) [4]. The inability to effectively manage HCC has motivated the search for more effective treatments.

Presently, it is recognized that epithelial-mesenchymal transition (EMT) plays an important role in cancer progression. The reprogramming of gene expression during EMT, as well as non-transcriptional changes, are initiated and controlled by signal pathways that respond to extracellular cues [5]. Among these, transforming growth factor- $\beta$ (TGF- $\beta$ ) and TGF- $\beta$-related proteins have emerged as major inducers of this trans-differentiation process in development and cancer [6].
Arginine methylation is a common post-translational modification known to have a role in several cellular processes, including signal transduction, DNA repair, transcription, protein subcellular localization and RNA processing [7]. The protein arginine methyltransferase (PRMT) family is the main group of enzymes to methylate arginine residues. They are capable of modifying diverse substrates, from histone components to specific nuclear and cytoplasmic proteins [8]. PRMT1 is the predominant PRMT in mammalian cells and could contribute to over $80 \%$ of all the cellular PRMT activities [9]. Dysregulated PRMT1 expression has been observed in a number of human tumors, including lung [10], esophagus [11], colon [12], glioma [13] and breast [14]. Previous studies also have found that PRMT1 is an important regulator of EMT. They found Twist 1 [10], FAM98A [15] or ZEB1 [14] as a new substrate of PRMT1, which was required for the process of EMT and tumor cell migration and invasion. Other research has suggested that exogenous expression of miR-503 dramatically suppressed EMT via 
PRMT1 in hepatic carcinoma cells [16]. They all proved that PRMT1 is a key regulator of EMT and promotes the ability of migration and invasion in tumor cells. However, the direct impact of PRMT1 on hepatic carcinoma and which signaling pathway it influences on is still unknown.

In this study, we identify that PRMT1 is aberrantly expressed in hepatic carcinoma tissues compared with normal liver tissues, and is critical for the ability of proliferation, migration and invasion in hepatic carcinoma cells in vitro. We also find that PRMT1 promotes EMT probably via TGF- $\beta 1 /$ Smad signaling in hepatic carcinoma cells. These findings prove that PRMT1 might play a crucial role in liver cancer progression.

\section{Materials and methods}

Cells and cell culture. The hepatic carcinoma cells HepG2, SMMC-7721 and Bel-7402 were obtained from Shanghai Cancer Institute and have been tested and authenticated by short tandem repeat analysis. Cells were cultured with DMEM (Multicell, China) supplemented with 10\% FBS, in humidified $5 \% \mathrm{CO}_{2}$ incubator at $37^{\circ} \mathrm{C}$.

Western blotting. The cultured cells were rinsed with cold PBS before treated with $1 \times$ SDS loading buffer at $100^{\circ} \mathrm{C}$ for $10 \mathrm{~min}$. Then the mixture was centrifuged at $12,000 \times \mathrm{g}$ for $5 \mathrm{~min}$. About $10 \mu \mathrm{l}$ of protein was loaded into each lane, separated by $10 \%$ SDS-PAGE and then transferred to the PVDF membrane. The membrane was blocked by $5 \%$ non-fat milk powder for $1 \mathrm{~h}$ at room temperature and then incubated with primary antibodies at $4^{\circ} \mathrm{C}$ overnight. The membranes were washed with TBS-T buffer (10 mM Tris$\mathrm{HCl}, \mathrm{pH} 7.4,150 \mathrm{mM} \mathrm{NaCl}, 0.05 \%$ Tween 20) for $15 \mathrm{~min}$ and incubated with HRP-labeled secondary antibodies. The antibodies were mouse anti-PRMT1 (Santa Cruz Biotechnology, sc-166963), mouse anti- $\beta$-Tubulin (Cell Signaling, No 6181), mouse anti-Flag (SIGMA, F1804), and all other antibodies - rabbit anti-N-Cadherin (No 13116), rabbit anti-E-Cadherin (No 3195), rabbit anti-Vimentin (No 5741), rabbit anti-Snail (No 3879), rabbit anti-TGF- $\beta$ (No 3711), rabbit anti-Smad2 (No 5339), rabbit anti-p-Smad2 (No 3108), rabbit anti-Smad3 (No 9523), and rabbit anti-pSmad3 (No 9520) were from Cell Signaling.

Real-time PCR. Total RNA was isolated using RNAiso Plus (Takara). Reverse transcription was performed using RevertAid First Strand cDNA Synthesis Kit (Thermo) according to the manufacturer's recommendations. The SYBR greenbased Real-time PCR was then performed in triplicate using CFX-96 Sequence Detection System (Bio-Rad) The primer pair been used for the amplification of the human PRMT1 gene was as follows: forward primer, 5'-CATGGAGGACTACCTGAC-3', and reverse primer, 5'-GTTGTTCTTGGCGTTGGG-3'. As an internal standard, a fragment of human GAPDH was amplified by PCR using the following primers: forward primer, 5'-GGTGAAGGTCGGTGTGAACG-3', and reverse primer, 5'-CTCGCTCCTGGAAGATGGTG-3'. The relative fold change in RNA expression was calculated using the $2^{-\Delta \Delta \mathrm{Ct}}$ method.

Immunohistochemical staining and scoring. Eightyeight patients with hepatocellular carcinoma from the Department of Surgery, Eastern Hepatobiliary Hospital and the Department of Medical Oncology, Changzheng Hospital, Shanghai, China from 2004 to 2008 were enrolled in this study.

In this study, immunohistochemistry (IHC) was performed on tissue-microarrays. IHC was done following the standard protocol of Peroxidase Conjugated Mouse/ Rabbit IgG SABC Kit (SA1020, Boster Biological technology). A mouse monoclonal antibody against PRMT1 (sc-166963, Santa Cruz Biotechnology; 1:50 dilution) was used as the primary antibody and biotinylated goat anti-mouse/ anti-rabbit IgG (Boster Biological technology) was used as a secondary antibody. The chromogenic reaction was carried out with a DAB chromogenic kit (AR1022, Boster Biological technology) for 5 minutes, resulting in the expected browncolored signal. Finally, after rinsing with deionized water, the slides were counterstained with hematoxylin, dehydrated, mounted with mounting medium (D0547, Boster Biological Technology) and cover slip. Evaluation of immunohistochemical staining intensity was scored from 0 to 3 (0, negative; 1 , weak; 2 , moderate; 3 , strong).

Plasmid construction. The entire PRMT1 sequence was amplified with RT-PCR using primers PRMT1-allF: 5'-GAGGCGATCGCATGGCGGCAGCCGAGGCCGCGA-3', and PRMT1-all-R: 5'-GCGACGCGTGCGCATCCGGTAGTCGGTGGAGCA-3', and then inserted into the AsiSI and MluI site of the pCMV6-Entry plasmid (Origene) and ligated into the vector. The EGFP and PRMT1 shRNA oligos were firstly annealed into double strands and then cloned into pLKO.1-puro-vector (Addgene).

Generation of stable cell lines. To produce cells that constitutively expressed small hairpin RNA or short hairpin RNA (shRNA), oligonucleotides encoding shRNA specific for PRMT1 5'-GCAACTCCATGTTTCATAATTCAAGAGATTATGAAACATGGAGTTGC-3') were cloned into the pLKO.1-puro-vector. The packaging plasmid $\mathrm{psPA} \times 2$ and the envelope plasmid pMD2.G were purchased from Sigma (MO, USA). pLKO.1-sh-PRMT1 vector was co-transfected with psPA $\times 2$ and pMD2.G into HEK293T cells using Lipofectamine 2000 (Invitrogen). Viruses were harvested $48 \mathrm{~h}$ and $72 \mathrm{~h}$ after transfection and viral titers were determined. Cells were infected with $1 \times 10^{6}$ recombinant lentivirus transduction units in the presence of $8 \mathrm{mg} / \mathrm{ml}$ polybrene (Sigma, MO, USA). Puromycin $(1 \mu \mathrm{g} / \mathrm{ml})$ was added to cells until the cells in blank group died off. The survived cells were stable infected cells. Similarly, HCC cells were transfected with Flag-PRMT1 by using Lipofectamine 2000 reagent according to the manufacturer's protocol and the positive clones were selected by G418 at the concentration of $200 \mu \mathrm{g} / \mathrm{ml}$.

Colony-forming assay. Stable cell lines - Bel-7402, SMMC-7721 and HepG2 cells were harvested, resuspended 
in medium and transferred to the six well plate $(500,1000$, 2000 cells per well) for 10-14 days until large colonies were visible. Colonies were fixed in $4 \%$ paraformaldehyde for $30 \mathrm{~min}$ and then stained with $0.05 \%$ crystal violet for $30 \mathrm{~min}$, and the number of colonies was counted or photomicrographs were taken under phase-contrast microscope.

Wound healing assay. Cells have grown to confluence in complete cell culture medium. At time 0 , a scrape wound was created across the diameter with a $10 \mu \mathrm{l}$ pipette tip followed by extensive washes with medium to remove dead and floating cells and cultured with serum-free medium. The distance was recorded at $0 \mathrm{~h}$ and $24 \mathrm{~h}$. Images were captured using an inverted microscope equipped with a digital camera. Before the experiment, a marker was made under the plate, to make sure the pictures taken at different time were from the same place in each well. The relative migration rate was calculated according to the distances between the two lines. The distance at time $0 \mathrm{~h}$ and $24 \mathrm{~h}$ was recorded as $\mathrm{D}_{0}$ and $\mathrm{D}_{24}$. The relative migration rate $=\left(D_{0}-D_{24}\right) / D_{0}$.

Migration assay and invasion assay. For assessing cell migration, $1 \times 10^{5}$ cells in serum free media were seeded into the transwell inserts (Corning) containing $8 \mu \mathrm{m}$ permeable pores and were allowed to migrate toward $10 \%$ FBS-containing medium. 24-36 h later, the migrated cells on the bottom of the insert were fixed with $4 \%$ paraformaldehyde solution followed by crystal violet (1\%) staining. Pictures were taken after washing the inserts three times with PBS. Five independent fields were counted for each transwell and the average numbers of cells/field were represented in the graphs. For assessing cell invasion, $1 \times 10^{5}$ cells in serumfree medium were seeded in the transwell inserts which had already been covered with a layer of BD Matrigel Basement Membrane. The cells were later processed similarly to that of cell migration assay. Finally, invaded cells were counted and the relative number was calculated.

Immunofluorescence. Cells were seeded on glass cover slips in 24-well plates and grown for $48 \mathrm{~h}$. Routinely, cells were washed twice with PBS, fixed with ice-cold $100 \%$ methanol for $15 \mathrm{~min}$ at $-20^{\circ} \mathrm{C}$, and blocked with $3 \%$ BSA in PBS for $1 \mathrm{~h}$. Cells were incubated with primary antibody overnight at $4{ }^{\circ} \mathrm{C}$. The following antibodies were used: PRMT1 (Santa Cruz), E-cadherin (Cell Signaling). Then, cells were incubated with Cy3-Labeled goat anti-rabbit IgG (Beyotime Biotechnology) secondary and Alexa Fluor 488 goat anti-mouse IgG (Invitrogen) antibodies for $2 \mathrm{~h}$ at room temperature in the dark, DAPI $(1 \mu \mathrm{g} / \mathrm{ml}$, Pierce, USA) counter stain was used for nuclear staining. After extensive washing, the cover slips were then mounted on glass slides, and the fluorescent images were captured with a fluorescent microscope and a SPOT CCD camera.

Luciferase assay. Luciferase reporter assays were performed in 24-well plates and $100 \mathrm{ng}$ of the appropriate firefly luciferase construct (SMAD luciferase reporter plasmid) was co-transfected with $20 \mathrm{ng}$ of Renilla luciferase pRL-SV40 reporter and 500 ng of Flag-PRMT1/sh-PRMT1.
Upon co-transfection, hepatocellular carcinoma cells were cultured for $48 \mathrm{~h}$, respectively. Luciferase activity was determined using dual luciferase reporter system (Promega).

Retrospective analysis of PRMT1 gene expression in human liver cancer. Correlations between liver sample type, patient survival, tumor recurrence and PRMT1 gene expression were determined through analysis of TCGA, Roessler and Guichard Liver datasets respectively, which are available through Oncomine (Compendia Biosciences, www.oncomine.org). High and low groups were defined as above and below the mean, respectively. The protein level of PRMT1 in liver and hepatocellular carcinoma tissues were determined through analysis of The Human Protein Atlas (www.proteinatlas.org).

Statistical analysis. All grouped data is presented as mean \pm standard error from at least three independent experiments. Differences between groups were assessed by ANOVA or Student's t-test using GraphPad Prism5 software. For survival analysis, Kaplan Meier curves were generated using GraphPad Prism5 software and log-rank analysis performed. A p-value $<0.05$ was considered as statistically significant.

\section{Results}

Upregulated of PRMT1 in clinical liver cancer tissues. To confirm the clinical relevance of PRMT1 expression, we first analyzed the mRNA levels of PRMTs from oncomine (www.oncomine.org), Roessler Liver datasets [17] (Figure 1A), and found significant upregulation of PRMT1 in liver tumor tissues compared to liver non-tumor tissues (liver non-tumor tissue $\mathrm{N}=21$; hepatic carcinoma $\mathrm{N}=22$; $\mathrm{p}=0.0007$, Figure 1B). To evaluate protein expression levels of PRMT1 in liver tissues, we analyzed the human protein atlas datasets [18] (www.proteinatlas.org). We observed strong PRMT1 staining in liver cancer tissues, but very weak staining in normal liver tissues (Figure 1C). All these data indicate that PRMT1 expression is significantly upregulated in clinical liver cancer tissues.

To evaluate protein expression levels of PRMT1 in hepatic carcinoma tissues, we performed immunohistochemical analysis using anti-PRMT1 antibodies (Figure 1D). We observed strong PRMT1 staining in hepatic carcinoma tissues. These data indicate that PRMT1 is significantly upregulated in HCC tissues and is associated with the ability of cell proliferation.

PRMT1 knockdown inhibits the ability of proliferation in hepatic carcinoma cells. Previous study identifies that PRMT1 expression is upregulated in cancers and important for cancer cell proliferation [19]. To determine the role of PRMT1 in hepatic carcinoma progression, we first examined the expression level of PRMT1 in HL-7702, HepG2, SMMC-7721 and Bel-7402 cells using real-time PCR and western blot, and found that PRMT1 expression, at both mRNA and protein levels, was lower in HL-7202 cells than in HepG2, Bel-7402 and SMMC-7721 cells (Figures 2A and B). 


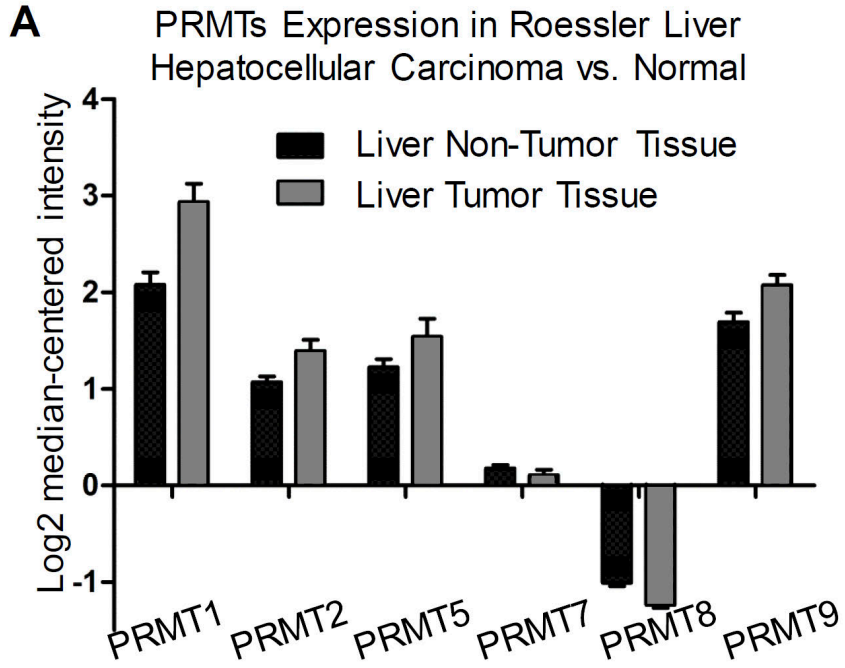

C The human protein atlas datasets

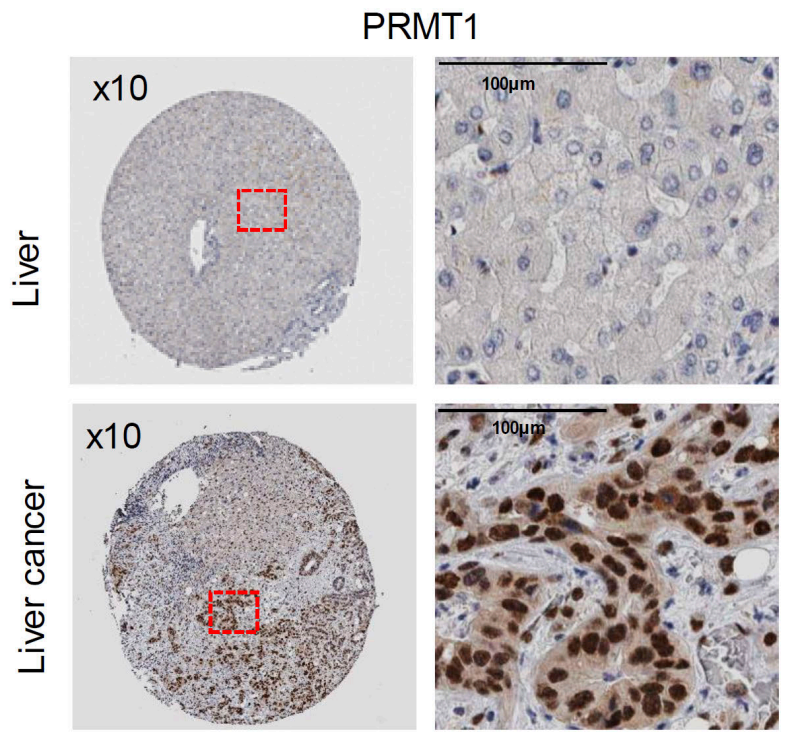

B PRMT1 Expression in Roessler Liver Hepatocellular Carcinoma vs. Normal

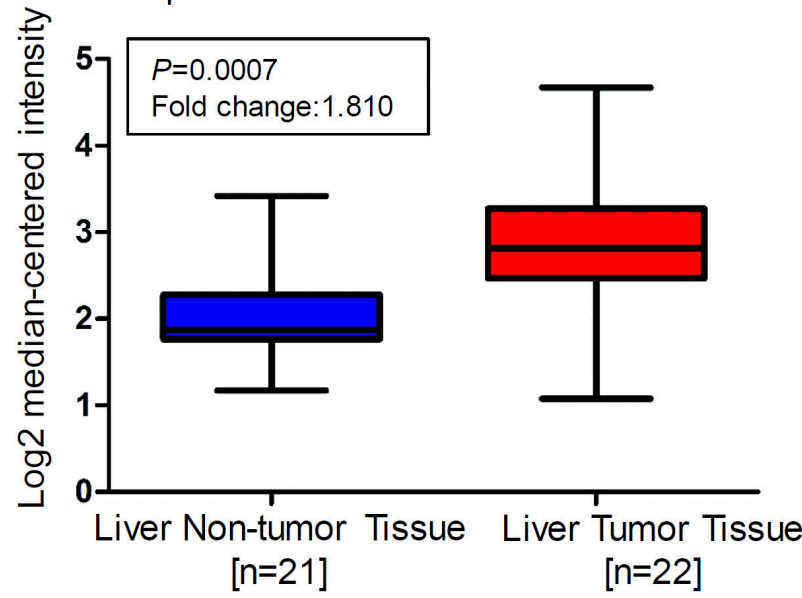

D Clinical $\mathrm{HCC}$ tissues

\section{PRMT1}
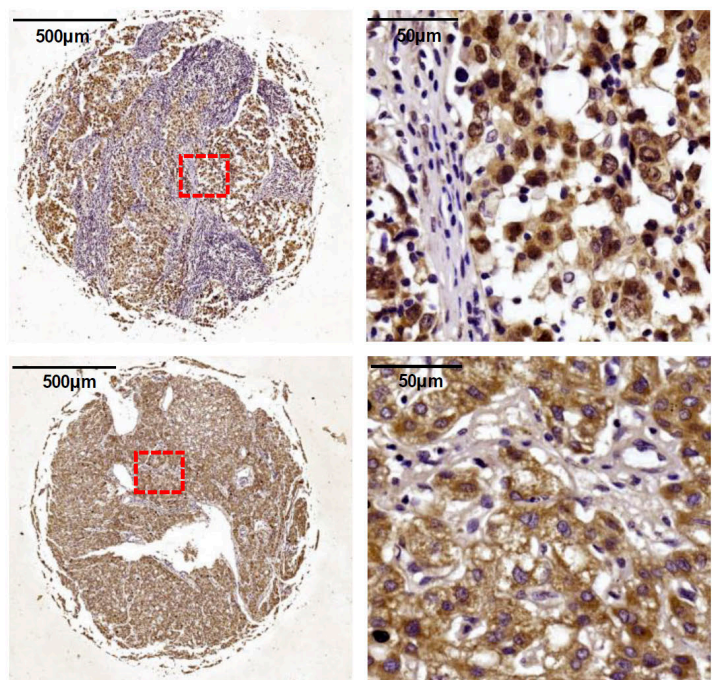

Figure 1. Elevated PRMT1 expression in hepatic carcinoma. A and B) Oncomine analysis of the Roessler database indicates elevated PRMT1 mRNA expression in hepatic carcinoma compared with normal (liver $\mathrm{N}=21$; hepatocellular carcinoma $\mathrm{N}=22 ; \mathrm{p}=0.0007$ ). C) The human protein atlas datasets show that the protein level of PRMT1 in liver cancer tissues is higher than that in normal liver tissues, scale bar $100 \mu \mathrm{m}$. D) Immunohistochemical staining of PRMT1 in clinical hepatic carcinoma tissues, scale bar $500 \mu \mathrm{m}$ and $50 \mu \mathrm{m}$.

The expression level of PRMT1 in these cells was consistent with the migration ability, implying that PRMT1 upregulation might be involved in metastasis of hepatic carcinoma cells (Figure S1A). We then examined whether PRMT1 expression was required for the proliferation in hepatic carcinoma cells. Bel-7402 and SMMC-7721 cells were transfected with sh-EGFP or sh-PRMT1 and proliferation ability was evaluated. The transfection of PRMT1 shRNA sufficiently depleted PRMT1 expression, knocking down the expression level of PRMT1 in Bel-7402 and SMMC-7721 cells for about $75 \pm 3 \%$ and $65 \pm 5 \%$, respectively (Figure 2C). Moreover, the ability of cell colony formation was also suppressed by PRMT1 depletion. Bel-7402 cells and SMMC-7721 cells expressing sh-PRMT1 showed reduced colony number when compared with cells expressing sh-EGFP ( $410 \pm 22$ vs. $60 \pm 18$ and $382 \pm 26$ vs. $85 \pm 20, p<0.01$, Figure $2 \mathrm{E}$ ). On the contrary, overexpression of PRMT1 in HepG2 and SMMC-7721 cells promotes the ability of cell colony formation $(271 \pm 11$ vs. $425 \pm 20$ and $268 \pm 32$ vs. $419 \pm 21, \mathrm{p}<0.05$, Figure $2 \mathrm{~F}$ ). The overexpression of PRMT1 in HepG2 and SMMC-7721 cells was increased 


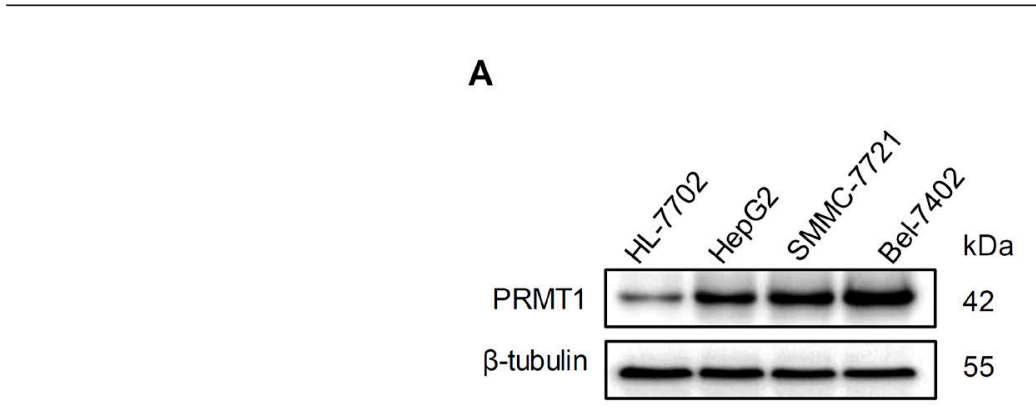

C
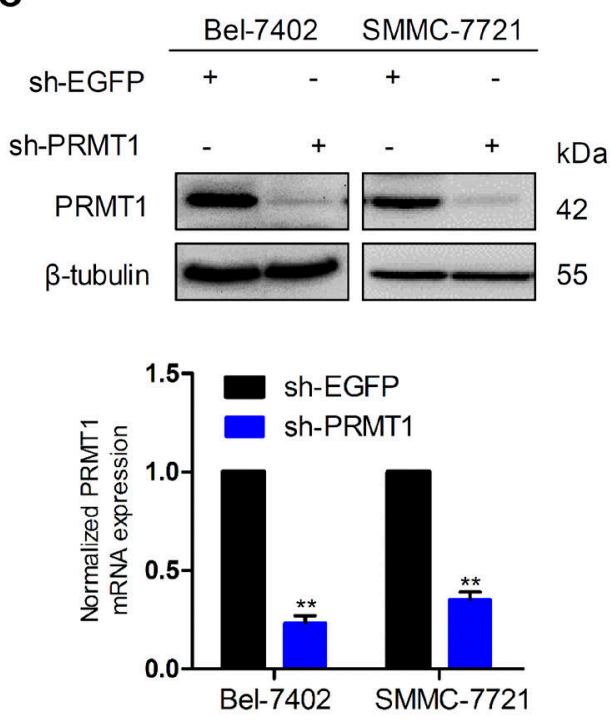

E

Figure 2. PRMT1 knockdown results in reduced cell proliferation. A) The expression of PRMT1 in hepatic carcinoma cells was examined by western blotting. B) The mRNA level of PRMT1 in hepatic carcinoma cell lines was examined by using RT-PCR. C) PRMT1 knockdown in Bel-7402 and SMMC-7721 cells. D) PRMT1 overexpression in HepG2 and SMMC-7721 cells. E) Colony-forming assay to examine the effects of knocking down PRMT1 on the growth of Bel-7402 and SMMC-7721 cells. F) Colonyforming assay to examine the effects of overexpressed PRMT1 on the growth of HepG2 and SMMC7721 cells. ${ }^{*} \mathrm{p}<0.05,{ }^{* *} \mathrm{p}<0.01$.

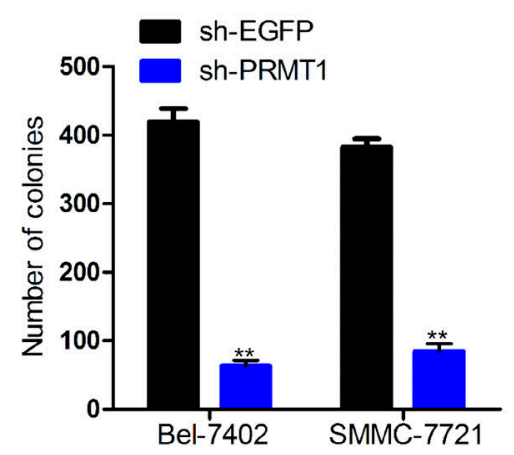

B

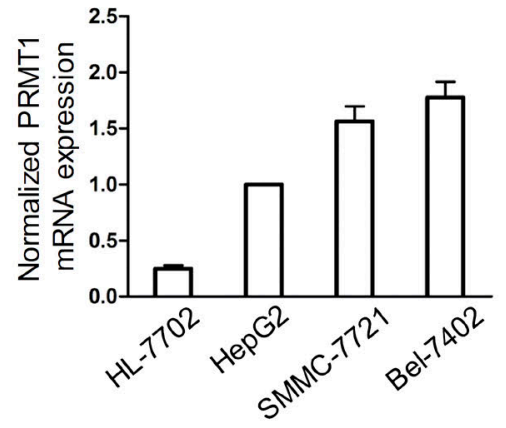

D
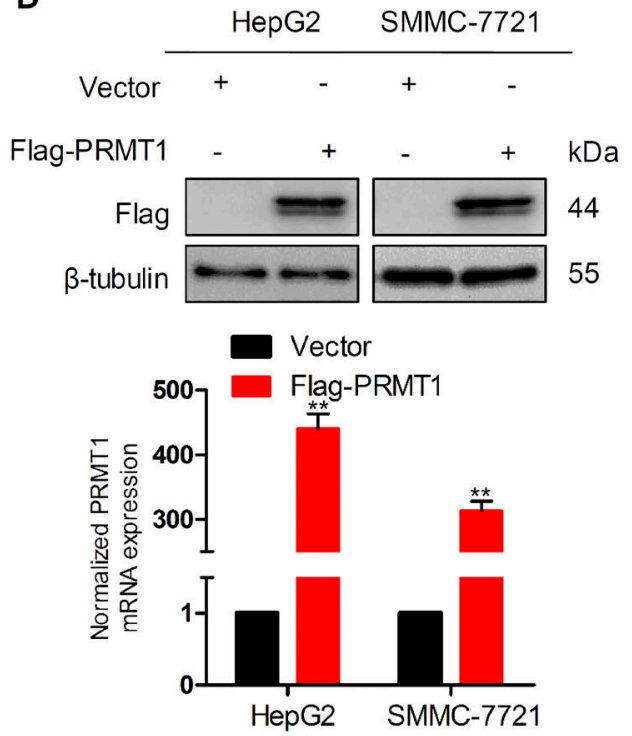

$\mathbf{F}$

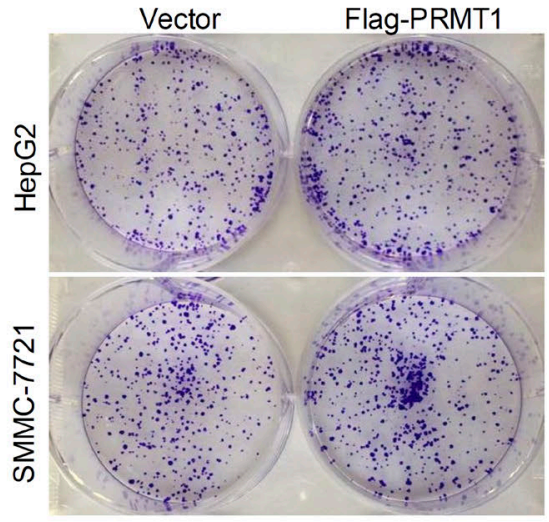


by 400 and 300 fold, respectively (Figure 2D). These results reveal that PRMT1 knockdown inhibits the ability of proliferation in hepatic carcinoma cells (Figures S1B and S1C).

PRMT1 is required for cell migration. We then explored whether PRMT1 could also affect cell migration, we performed wound-healing assays. For these assays, a scrape wound was created on confluent cultures of Bel-7402 and SMMC-7721 cells expressing either sh-EGFP or sh-PRMT1. Bel-7402 and SMMC-7721 cells expressing sh-PRMT1 displayed reduced motility in comparison to Bel-7402 and SMMC-7721 cells expressing sh-EGFP after $24 \mathrm{~h}$ (Figure 3A). By contrast, another scrape wound was created on confluent cultures of HepG2 and SMMC-7721 cells expressing either Vector or Flag-PRMT1. HepG2 and SMMC-7721 cells expressing Flag-PRMT1 shown enhanced motility compared to HepG2 and SMMC-7721 cells expressing Vector after $24 \mathrm{~h}$ (Figure 3B). We have also tested the migratory potential of Bel-7402 and SMMC-7721 clones by using a transwell assay. The migrated cells on the bottom of the insert were later fixed, stained, counted and are represented in the graphs (Figure 3C). Bel-7402 cells and SMMC-7721 cells expressing sh-PRMT1 showed reduced migration when compared with cells expressing sh-EGFP ( $457 \pm 32$ vs. $86 \pm 18$ and $382 \pm 26$ vs. $85 \pm 20, \mathrm{p}<0.01$, Figure $3 \mathrm{C}$ ). Conversely, overexpression of PRMT1 in HepG2 and SMMC-7721 cells was found to increase cell migration $(79 \pm 21$ vs. $280 \pm 20$ and $125 \pm 16$ vs. $308 \pm 20, \mathrm{p}<0.01$, Figure $3 \mathrm{D}$ ). These results suggest that PRMT1 promotes the ability of migration in hepatic carcinoma cells.

PRMT1 promotes the ability of invasion in hepatic carcinoma cells. To measure the invasive abilities of Bel-7402 and SMMC-7721 cells expressing shPRMT1, we performed invasion assays. The cells that have invaded the Matrigel and migrated through the pores were fixed, stained, counted and are represented in the graphs (Figure 4A). Bel-7402 cells and SMMC-7721 cells expressing sh-PRMT1 showed reduced invasion when compared with cells expressing sh-EGFP ( $269 \pm 28$ vs. $75 \pm 17$ and $295 \pm 26$ vs. $80 \pm 25, \mathrm{p}<0.01$, Figure 4A). On the contrary, overexpression of PRMT1 in HepG2 and SMMC-7721 cells promotes invasion $(105 \pm 16$ vs. $284 \pm 23$ and $120 \pm 24$ vs. $316 \pm 20, \mathrm{p}<0.01$, Figure $4 \mathrm{~B}$ ). MMP2 and MMP9 belong to matrix metallopeptidases. Matrix metalloproteinases (MMPs) are major hydrolytic enzymes targeting extracellular matrix (ECM) during metastasis and there is a clear connection between MMPs, ECM degradation and cancer cell invasion [20]. The expression of MMP2 and MMP9 was examined by western blotting in hepatic carcinoma cells. Bel-7402 and SMMC-7721 cells with stable expression of sh-PRMT1 showed lower expression of MMP2 and MMP9 compare to cells with stable expression of sh-EGFP. Conversely, overexpression of PRMT1 showed higher expression of MMP2 and MMP9 in HepG2 and SMMC-7721 cells (Figures 4C and D). Moreover, the expression of extracellular released MMP2 and MMP9 showed the same results (Figures $4 \mathrm{E}$ and $\mathrm{F}$ ). Thus, these data demon- strate that PRMT1 promotes the ability of invasion in hepatic carcinoma cells.

PRMT1 promotes EMT via TGF- $\beta 1 /$ Smad signaling. The transdifferentiation of epithelial cells into motile mesenchymal cells, a process known as epithelial-mesenchymal transition (EMT), is integral to development, wound healing as well as stem cell behavior, and contributes pathologically to fibrosis and cancer progression [5]. This tightly regulated process is associated with a number of cellular and molecular events. Morphology assay showed that knockdown and overexpression of PRMT1 could change the phenotype of hepatic carcinoma cells (Figures 5A and B). Then, we detected the EMT markers at the protein levels using western blotting. Our data suggested that PRMT1 knockdown resulted in downregulation of N-cadherin, Vimentin, Snail and upregulation of E-cadherin in Bel-7402 and SMMC-7721 cells (Figure 5C). In contrast, PRMT1 overexpression led to the opposite results in HepG2 and SMMC-7721 cells (Figure 5D). Moreover, immunofluorescence staining indicated that PRMT1 knockdown resulted in upregulation of E-cadherin in Bel-7402 and SMMC-7721 cells (Figure 5E) and PRMT1 overexpression led to downregulation of E-cadherin HepG2 and SMMC-7721 cells (Figure 5F). All these results confirmed that PRMT1 promotes EMT in hepatic carcinoma cells.

TGF- $\beta$ induces EMT in many biological processes [6], we detected the effects of PRMT1 on the classic TGF- $\beta$ / Smad signaling. We found that PRMT1 knockdown downregulated TGF- $\beta 1, p-S m a d 2$ and p-Smad 3 in Bel-7402 and SMMC-7721 cells (Figure 6A), while PRMT1 overexpression resulted in upregulation of the above-mentioned proteins (Figures 6B and S1D). Knocking down or overexpressing PRMT1 had no influence on total Smad2/3 protein. Furthermore, Luciferase assay suggested that PRMT1 could activate Smad (Figures 6C and 6D). Taken together, these data suggest that PRMT1 promotes EMT probably via TGF- $\beta 1 /$ Smad signaling in hepatic carcinoma cells.

PRMT1 correlates with liver tumor clinical outcomes and is connected with survival in many cancers. To confirm the clinical relevance of PRMT1 expression, we interrogated available liver tumor datasets (oncomine and cancer browser) for PRMT1. We identified several annotated liver tumor datasets in which we could compare PRMT1 expression in specimens with different sample types or recurrence or from patients with differential overall survival outcomes. PRMT1 was strongly correlated with sample type in TCGA database (Figure S2F-S2J), and the fold change in PRMT1 was higher and strongly significant (normal $\mathrm{N}=50$; primary tumor $\mathrm{N}=371 ; \mathrm{p}<0.0001$, Figure S3A). Further, PRMT1 was a negative prognostic factor for overall survival from Guichard Liver 2 database [21] (alive $\mathrm{N}=17$; dead $\mathrm{N}=8$; $\mathrm{p}=0.0447$, Figure S3B). To further evaluate the potential correlation of PRMT1 expression with patient outcome, we generated Kaplan-Meier survival curves from TCGA. PRMT1 is strongly associated with patient outcome of liver hepatic carcinoma (PRMT1 low $\mathrm{N}=67$; PRMT1 high $\mathrm{N}=74$; 
A

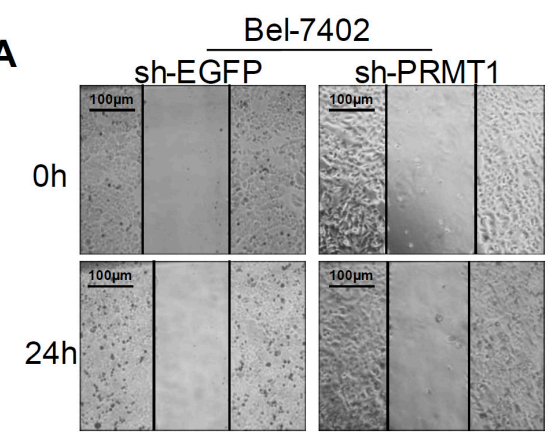

B

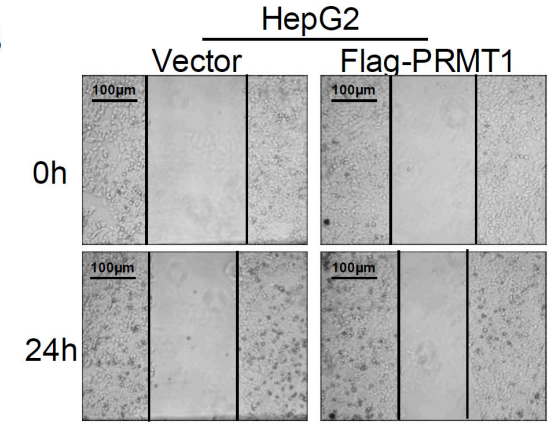

C
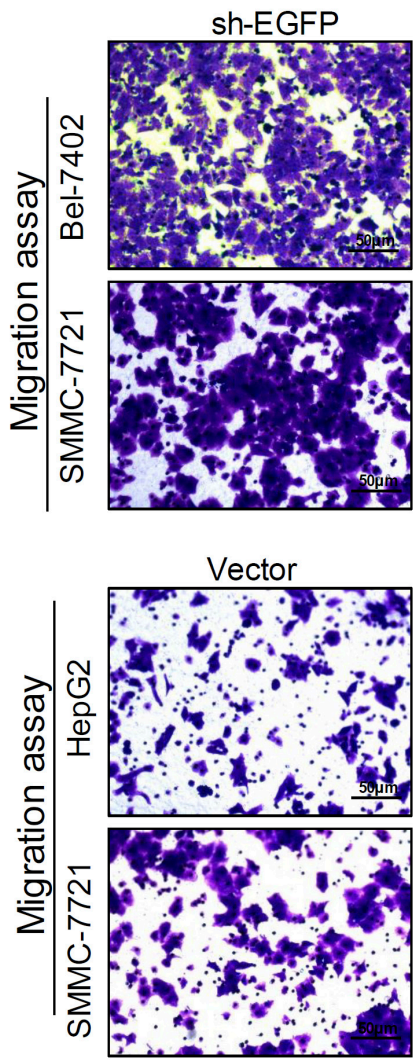

D
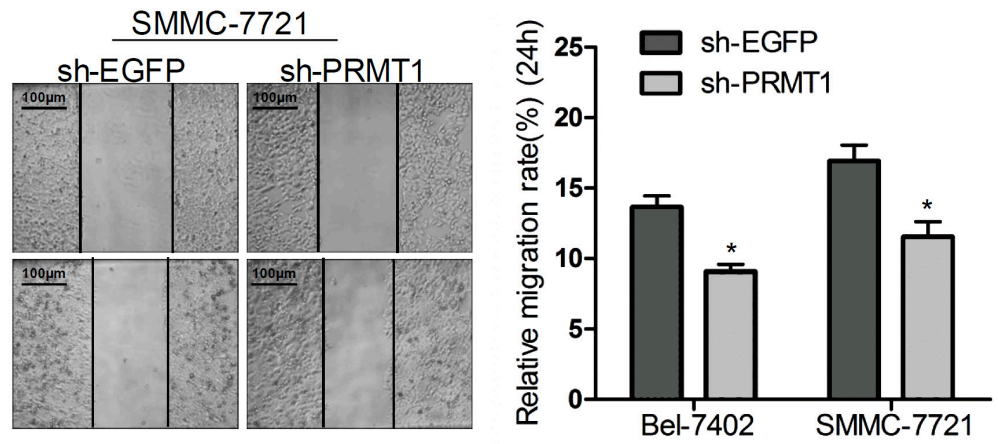
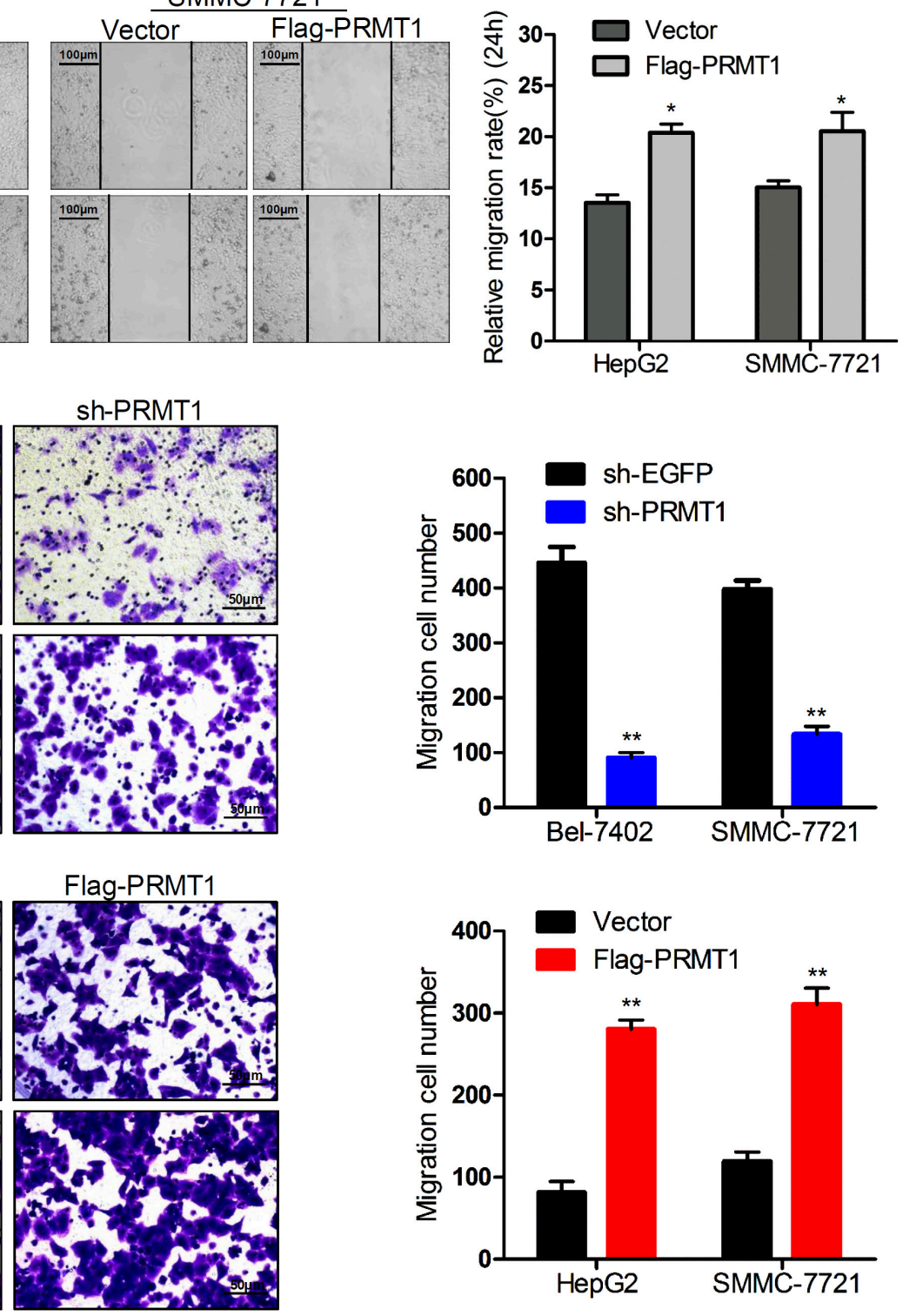

Figure 3. PRMT1 is required for cell migration. A) A scrape wound was created in confluent cultures of Bel-7402 and SMMC-7721 cells with stable expression of either sh-EGFP or sh-PRMT1, the distance of cell migration was recorded and the relative migration rate was calculated, scale bar $100 \mu \mathrm{m}$. ${ }^{*} \mathbf{p}<0.05$. B) A scrape wound was created in confluent cultures of HepG2 and SMMC-7721 cells with stable expression of either vector or Flag-PRMT1, the distance of cell migration was recorded and the relative migration rate was calculated, scale bar $100 \mu \mathrm{m}$. ${ }^{*} \mathrm{p}<0.05$. C) PRMT1 knockdown results in reduced cell migration in Bel-7402 cells and SMMC-7721 cells, the migration time was $24 \mathrm{~h}$, scale bar $50 \mu \mathrm{m}$. (D) PRMT1 promotes the ability of cell migration in HepG2 cells and SMMC-7721 cells, the migration time was $12 \mathrm{~h}$, scale bar $50 \mu \mathrm{m} .{ }^{* *} \mathrm{p}<0.01$. 
A

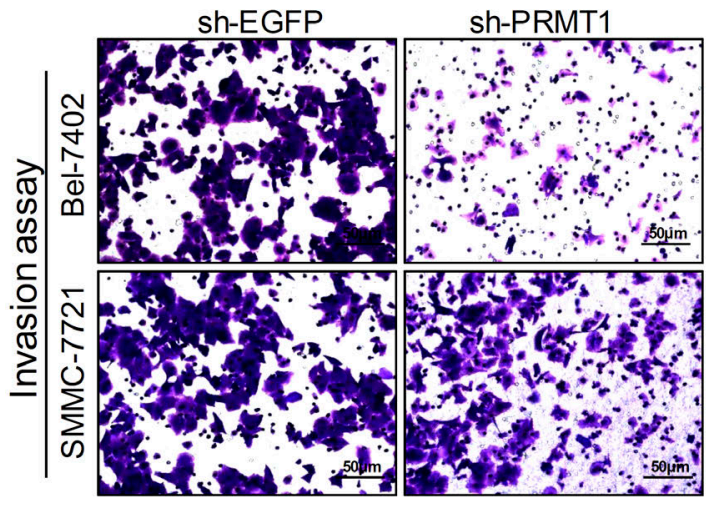

B

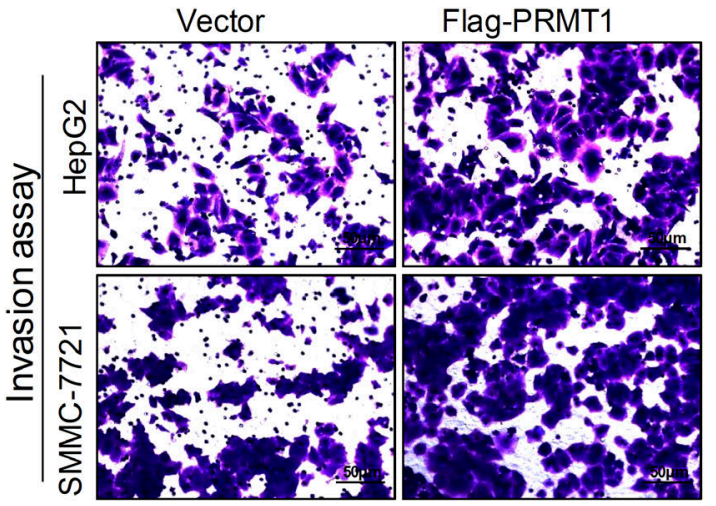

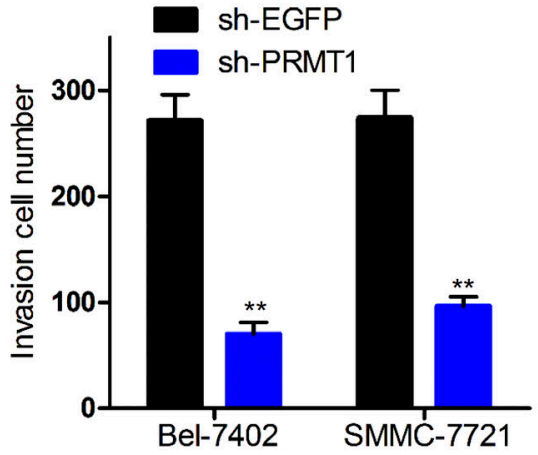

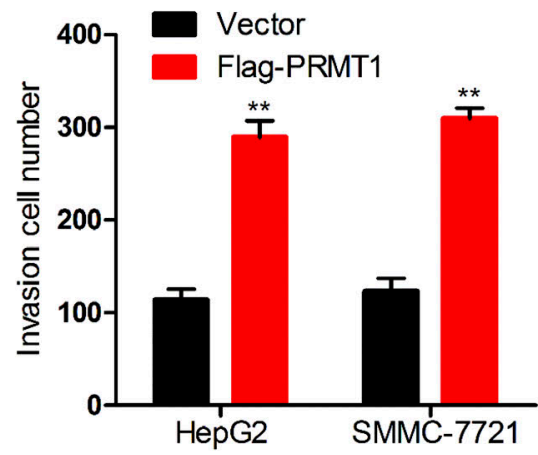

C

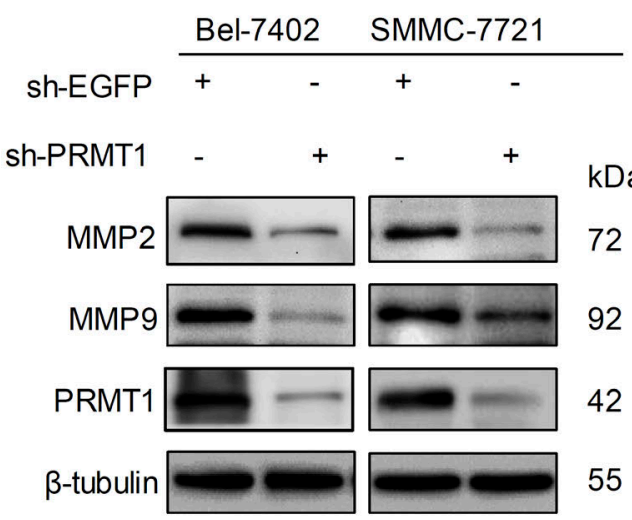

E
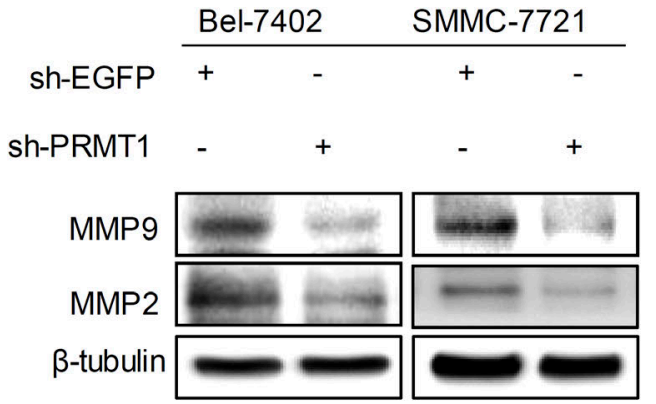

D

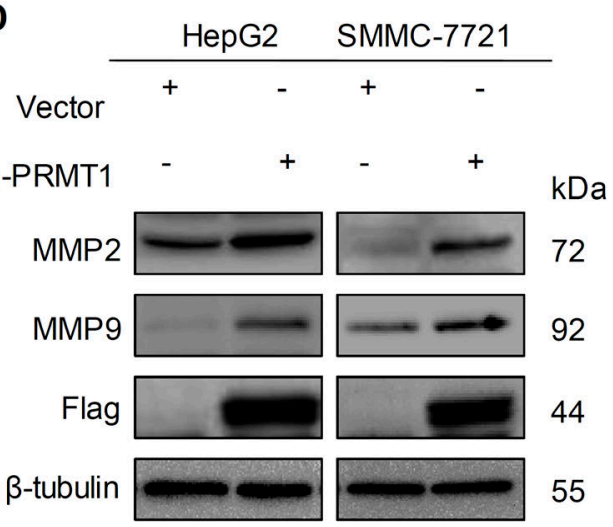

$\mathbf{F}$

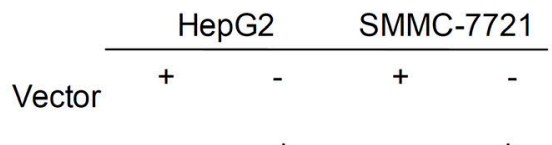

Flag-PRMT1

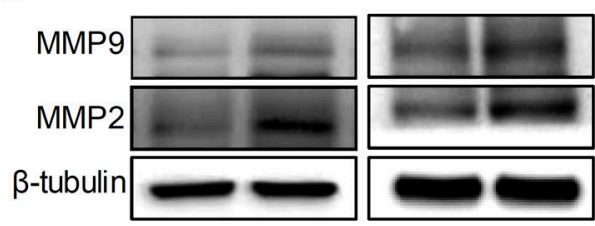

Figure 4. PRMT1 promotes cell invasion. A) PRMT1 knockdown inhibits the ability of invasion in Bel-7402 cells and SMMC-7721 cells, the invasion time was about $12 \mathrm{~h}$, scale bar $50 \mu \mathrm{m} .{ }^{* *} \mathbf{p}<0.01$. B) PRMT1 promotes the ability of cell invasion in SMMC-7721 cells and HepG2 cells, the invasion time was $12 \mathrm{~h}$, scale bar $50 \mu \mathrm{m} .{ }^{\star *} \mathrm{p}<0.01 . \mathrm{C}$ and D) MMP2 and MMP9 were examined using western blotting. E and F) The extracellular release of MMP2 and MMP9 were examined using western blotting. 
A

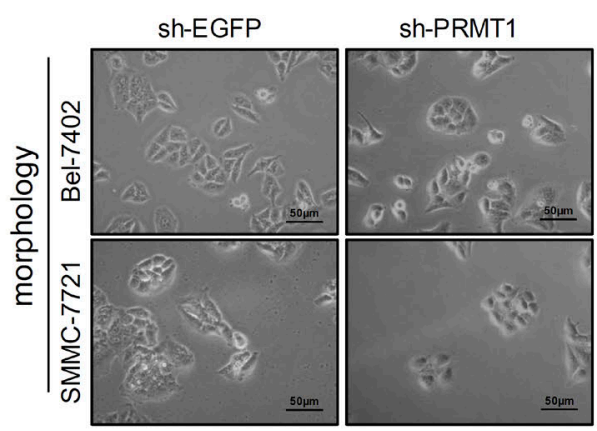

C

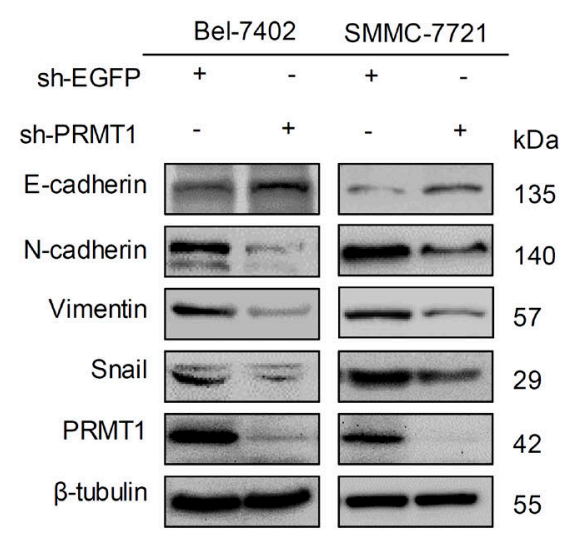

B

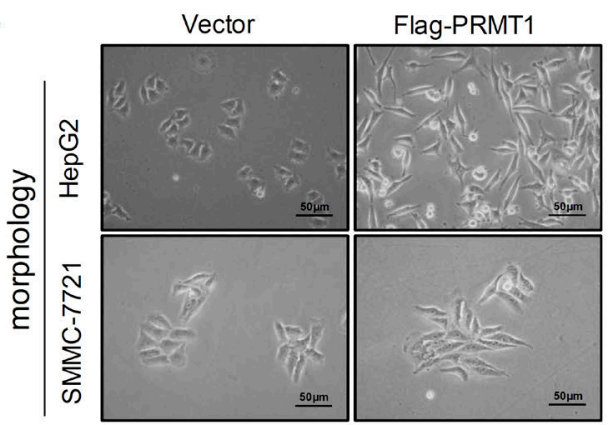

D

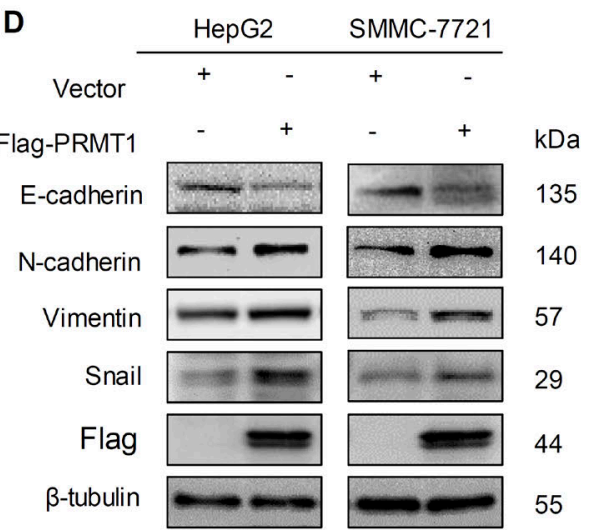

E

E-cadherin
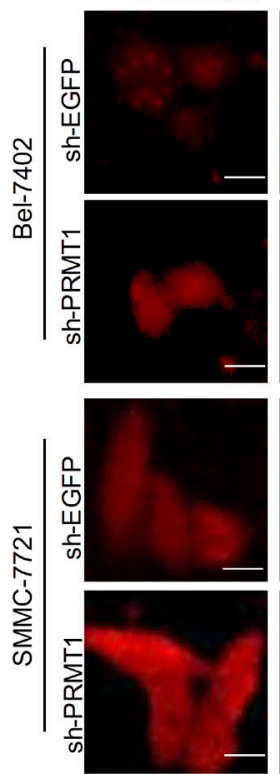

PRMT1
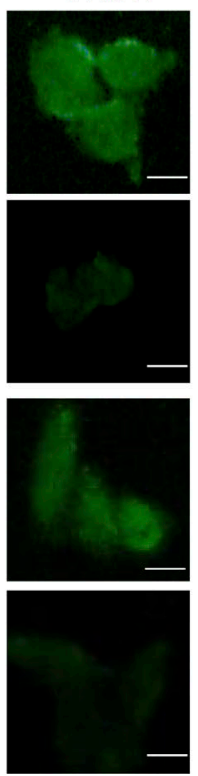

DAPI
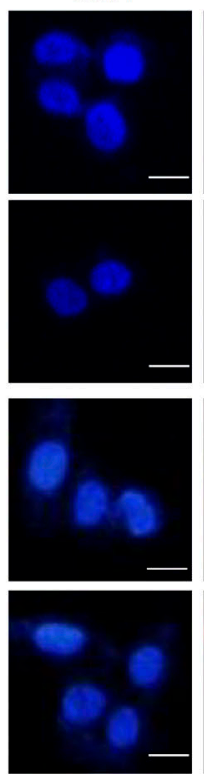

Merge
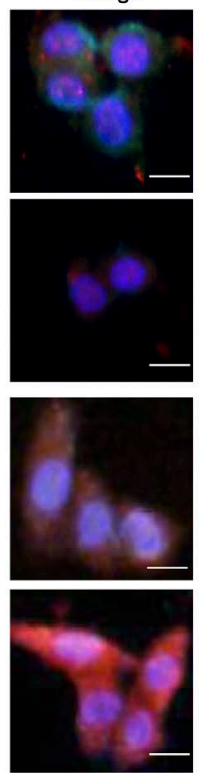

F E-cadherin
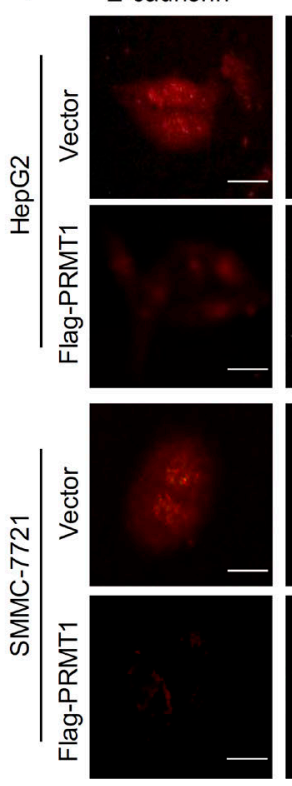

PRMT1

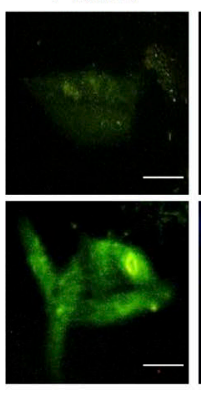

DAPI
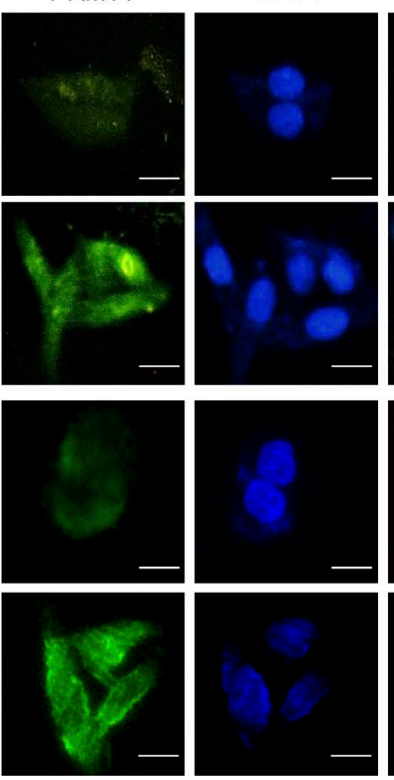

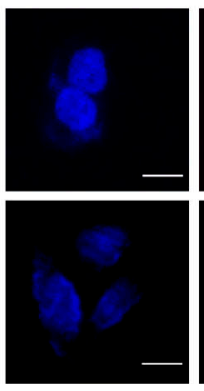

Merge
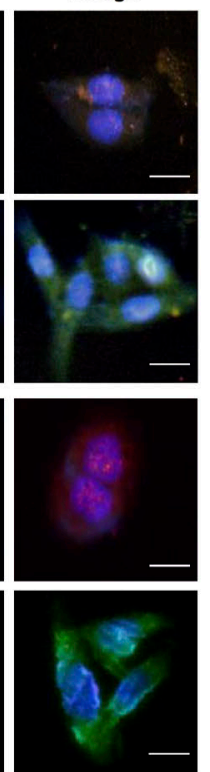

Figure 5. PRMT1 promotes EMT. A and B) The morphology of cells, scale bar $50 \mu \mathrm{m}$. C) PRMT1 knockdown in Bel-7402 and SMMC-7721 cells reverses the process of EMT, as detected by an increase in E-cadherin and decreases in N-cadherin, Vimentin and Snail. D) PRMT1 overexpression in HepG2 and SMMC-7721 cells promotes the process of EMT, as detected by a decrease in E-cadherin and increases in N-cadherin, Vimentin and Snail. E and F) Expression of EMT marker E-cadherin was analyzed by immunofluorescence, scale bar $10 \mu \mathrm{m}$.

$\mathrm{p}=0.0447$, Figure S3C). We, therefore, interrogated PRMT1 in relation to patient overall survival in other tumors. PRMT1 could have a role in patient outcomes in cancers beyond the liver (Figures S2A-S2E). Using TCGA, we found that PRMT1 expression correlated with poor overall survival in other digestive system tumors, including esophageal carcinoma (PRMT1 low $\mathrm{N}=31$; PRMT1 high $\mathrm{N}=41 ; \mathrm{p}=0.0429$, Figure S3D), pancreatic carcinoma (PRMT1 low $\mathrm{N}=46$; 
PRMT1 high $\mathrm{N}=38 ; \mathrm{p}=0.1620$, Figure S3E) and colon carcinoma (PRMT1 low $\mathrm{N}=17$; PRMT1 high $\mathrm{N}=17$; $\mathrm{p}=0.1625$, Figure S3F).

\section{Discussion}

In the current study, we identify that PRMT1 promotes the ability of proliferation, migration and invasion in hepatic carcinoma cells and induces EMT probably via TGF- $\beta 1$ / Smad signaling pathway. Importantly, these findings suggest that PRMT1 could represent a novel anti-cancer strategy.

Previous studies have determined that PRMT1 expression is upregulated in non-small cell lung cancer [10, 22], esophageal squamous cell carcinoma [11], colon cancer [12,
23], glioma [13, 24] and breast cancer [14, 25], indicating that elevated PRMT1 expression is a potential marker of the carcinogenesis process. In this study, we find that among PRMTs family members, the expression of PRMT1 is shown to be significantly upregulated in hepatic carcinoma cells at both mRNA and protein levels. We also found a great clinical significance of PRMT1 in a few databases. The overall survival outcomes show that the survival time of PRMT1 low patients is obviously longer than PRMT1 high patients in liver hepatic carcinoma. In other digestive cancers, including esophageal carcinoma, pancreatic adenocarcinoma and colon adenocarcinoma, the expression of PRMT1 also has a very high relevance with patient survival time. However, in other cancers, including lung cancer, lung adenocarcinoma,
A

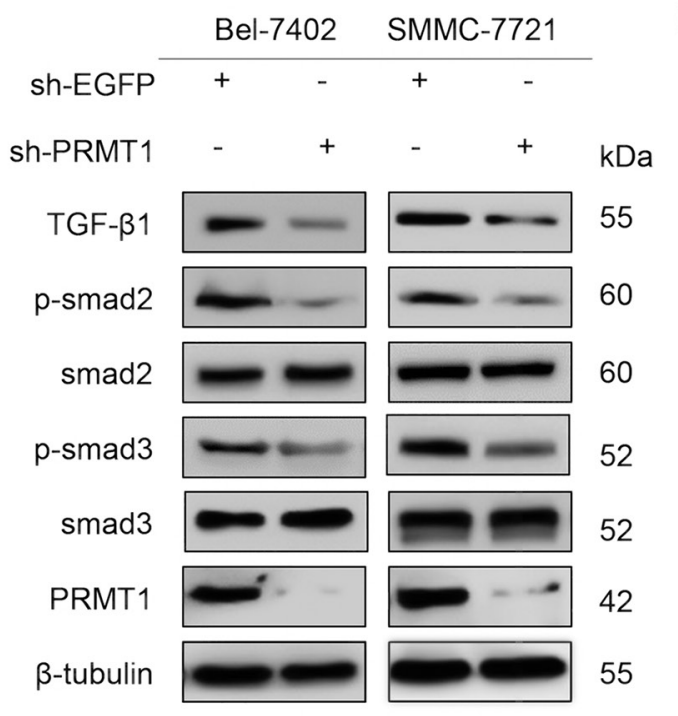

C

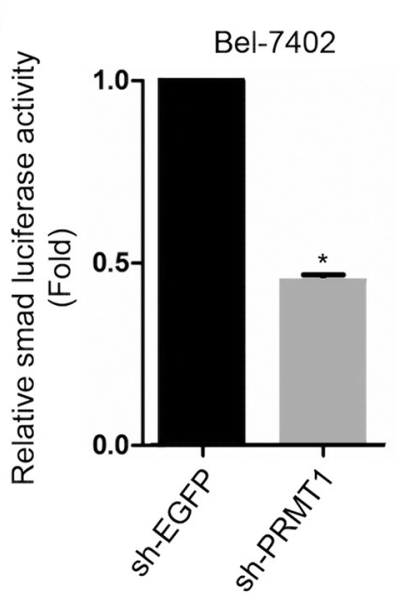

B

\begin{tabular}{|c|c|c|}
\hline & HepG2 & SMMC-7721 \\
\hline Vector & + & + \\
\hline
\end{tabular}

Flag-PRMT

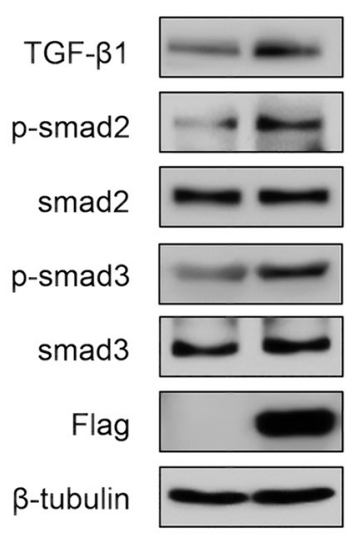

D

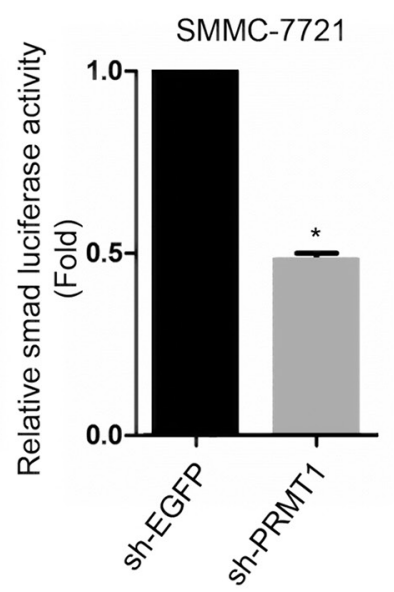

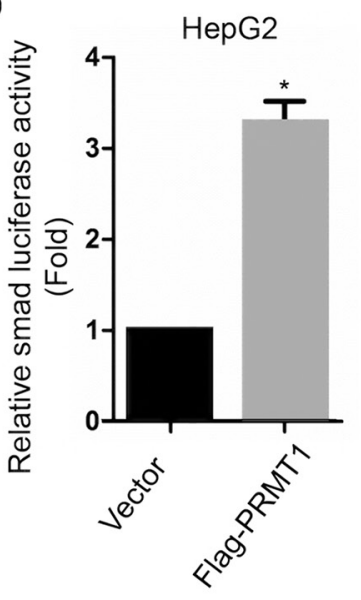

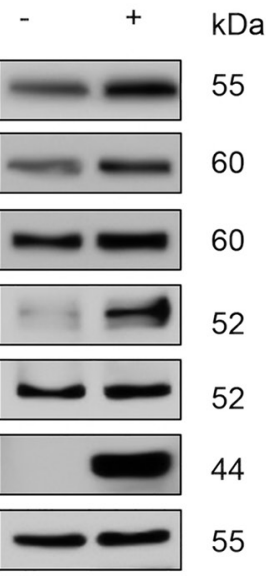

$\mathrm{kDa}$ 55

60

60

52

52

44

55

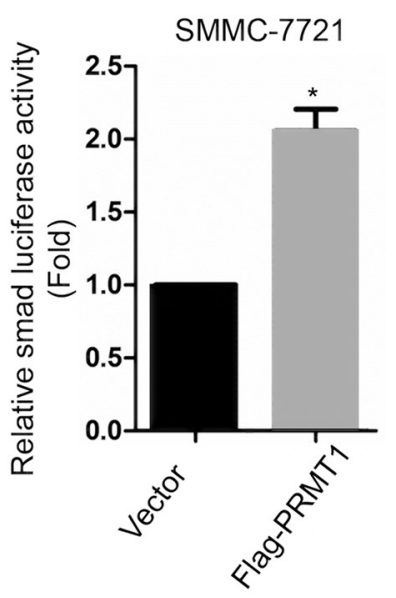

Figure 6. PRMT1 promotes EMT via TGF- $\beta 1 /$ Smad signaling pathway. A) Immunoblotting of TGF- $\beta 1$, Smad2/3, p-Smad2/3 in Bel-7402 and SMMC7721 cells treated with sh-EGFP or sh-PRMT1. Knockdown inhibits the activation of TGF- $\beta 1 /$ Smad signaling. $\beta$-tubulin was used as a loading control. B) Immunoblotting of TGF- $\beta 1$, Smad2/3, p-Smad2/3 in HepG2 and SMMC-7721 cells transfected with Vector or Flag-PRMT1. $\beta$-tubulin was used as a loading control. $\mathrm{C}$ and $\mathrm{D})$ The relative Smad luciferase activity, ${ }^{*} \mathrm{p}<0.05$. 
lung squamous cell carcinoma, breast invasive carcinoma, bladder urothelial carcinoma and glioblastoma multiforme, PRMT1 expression has no obvious relation to patient overall survival time. All these data suggest that PRMT1 may play a very special role in digestive system cancers and may be a potential new class of drug targets for future therapeutic treatments of cancer. In our study, we found that PRMT1 knockdown inhibited proliferation, while PRMT1 overexpression promoted proliferation instead, which indicated that PRMT1 is required for the ability of proliferation in hepatic carcinoma cells.

As we know, EMT is a complex phenomenon and the process of tumor cell migration and invasion are also associated with EMT [26, 27]. Loss of E-cadherin expression is considered as a key event during the induction of EMT [28]. In our study, we find that PRMT1 plays a key role in promoting tumor cell migration and invasion in hepatic carcinoma cells. We also identify PRMT1 as a key regulator of EMT, which is consistent with the previous results. PRMT1 knockdown increases the expression of E-cadherin and decreases the expression of $\mathrm{N}$-cadherin, Vimentin and Snail. On the contrary, PRMT1 overexpression gets the opposite results. In brief, PRMT1 induces EMT in hepatic carcinoma cells.

Additionally, abundant researches have shown that TGF- $\beta$ can induce EMT through many signaling pathways $[5,6,29]$. In TGF- $\beta$-induced EMT, Smad complexes can cooperate with transcription pathways in control of gene expression in EMT [6]. When TGF- $\beta$ is activated, Smad 2 is phosphorylated and undergoes dimerization with Smad3, thus allowing its translocation into nucleus in cancer cells, promoting the EMT progress [30]. In our research, we find that PRMT1 activate TGF- $\beta 1$ and its downstream effectors $\mathrm{p}-\mathrm{Smad} 2$ and $\mathrm{p}-\mathrm{Smad} 3$ in hepatic carcinoma cells. Furthermore, we find PRMT1 could activate Smad and then enhance its downstream effectors. Therefore, we speculate that PRMT1 promotes EMT probably via TGF- $\beta 1 /$ Smad pathway in hepatic carcinoma cells. Previous study has found that knockdown of PRMT1 resulted in increased Smurf2 expression as well as inhibition of TGF- $\beta$-mediated reporter activity [31]. Smurf2, a member of the HECT domain E3 ligase family, is well known for its role as a negative regulator of TGF- $\beta$ signaling by targeting Smads and TGF- $\beta$ receptor. Whether there are new substrates of PRMT1 that can influence TGF- $\beta /$ Smad are still necessary to confirm. Moreover, we need in vivo experiment to further support our conclusion.

In summary, our study provides a strong evidence for the involvement of PRMT1 in cancer cell proliferation, migration, and invasion and the induction of EMT. Our study also identified that PRMT1 induces EMT through activating TGF- $\beta 1 /$ Smad pathway. All these findings suggest that PRMT1 might be an important therapeutic target candidate to hepatic carcinoma. Thus, PRMT1 not only represents a unique class of EMT regulators but also represents a potential new class of drug targets for future anti-cancer therapeutic treatments.
Supplementary information is available in the online version of the paper.

Acknowledgements: This study was supported by grants from the National Natural Science Foundation of China (81472333, $81372718,81672402)$ and the Natural Science Foundation of Jiangsu Province (BK2013247), the Grants from the State Key Laboratory of Oncogenes and Related Genes (No.90-13-05) Specialized Research Fund for Senior Personnel Program of Jiangsu University (No. 13JDG108), "six one project" Research Projects of High-level Medical Personnel of Jiangsu Province (LGY2016054).

\section{References}

[1] WONG R, FRENETTE C. Updates in the management of hepatocellular carcinoma. Gastroenterol Hepatol (N Y) 2011; 7: 16-24.

[2] TABRIZIAN P, ROAYAIE S, SCHWARTZ ME. Current management of hepatocellular carcinoma. World J Gastroenterol 2014; 20: 10223-10237. https://doi.org/10.3748/wjg. v20.i30.10223

[3] ATTWA MH, EL-ETREBY SA. Guide for diagnosis and treatment of hepatocellular carcinoma. World J Hepatol 2015; 7: 1632-1651. https://doi.org/10.4254/wjh.v7.i12.1632

[4] TORRE LA, BRAY F, SIEGEL RL, FERLAY J, LORTETTIEULENT J et al. Global cancer statistics, 2012. CA Cancer J Clin 2015; 65: 87-108. https://doi.org/10.3322/ caac. 21262

[5] LAMOUILLE S, XU J, DERYNCK R. Molecular mechanisms of epithelial-mesenchymal transition. Nature reviews. Nat Rev Mol Cell Biol 2014; 15: 178-196. https://doi. org/10.1038/nrm 3758

[6] DERYNCK R, MUTHUSAMY BP, SAETEURN KY. Signaling pathway cooperation in TGF-beta-induced epithelial-mesenchymal transition. Curr Opin Cell Biol 2014; 31: 56-66. https://doi.org/10.1016/j.ceb.2014.09.001

[7] BALDWIN RM, MORETTIN A, COTE J. Role of PRMTs in cancer: Could minor isoforms be leaving a mark? World J Biol Chem 2014; 5: 115-129. https://doi.org/10.4331/wjbc. v5.i2.115

[8] GREENBLATT SM, LIU F, NIMER SD. Arginine methyltransferases in normal and malignant hematopoiesis. Exp Hematol 2016; 44: 435-441. https://doi.org/10.1016/j.exphem.2016.03.009

[9] WEI H, MUNDADE R, LANGE KC, LU T. Protein arginine methylation of non-histone proteins and its role in diseases. Cell Cycle 2014; 13: 32-41. https://doi.org/10.4161/cc.27353

[10] AVASARALA S, VAN SCOYK M, KARUPPUSAMY RATHINAM MK, ZERAYESUS S, ZHAO X et al. PRMT1 Is a Novel Regulator of Epithelial-Mesenchymal-Transition in Non-small Cell Lung Cancer. J Biol Chem 2015; 290: 1347913489. https://doi.org/10.1074/jbc.M114.636050

[11] ZHOU W, YUE H, LI C, CHEN H, YUAN Y. Protein arginine methyltransferase 1 promoted the growth and migration of cancer cells in esophageal squamous cell carcinoma. Tumour Bio. 2016; 37: 2613-2619. https://doi.org/10.1007/ s13277-015-4098-3 
[12] MATHIOUDAKI K, PAPADOKOSTOPOULOU A, SCORILAS A, XYNOPOULOS D, AGNANTI $\mathrm{N}$ et al. The PRMT1 gene expression pattern in colon cancer. Br J Cancer 2008; 99: 2094-2099. https://doi.org/10.1038/sj.bjc.6604807

[13] WANG S, TAN XC, YANG B, YIN B, PENG XZ. Screening of substrates of protein arginine methyltransferase 1 in glioma. Chin Med Sci J 2012; 27: 1-6.

[14] GAO Y, ZHAO Y, ZHANG J, LU Y, LIU X et al. The dual function of PRMT1 in modulating epithelial-mesenchymal transition and cellular senescence in breast cancer cells through regulation of ZEB1. Sci Rep 2016; 6: 19874. https:// doi.org/10.1038/srep19874

[15] AKTER KA, MANSOUR MA, HYODO T, ITO S, HAMAGUCHI $\mathrm{M}$ et al. FAM98A is a novel substrate of PRMT1 required for tumor cell migration, invasion, and colony formation. Tumour Biol 2016; 37: 4531-4539. https://doi. org/10.1007/s13277-015-4310-5

[16] Li B, Liu L, Li X, Wu L. miR-503 suppresses metastasis of hepatocellular carcinoma cell by TARGETING PRMT1. Biochem Biophys Res Commun 2015; 464: 982-987. https://doi. org/10.1016/j.bbrc.2015.06.169

[17] ROESSLER S, JIA HL, BUDHU A, FORGUES M, YE QH et al. A unique metastasis gene signature enables prediction of tumor relapse in early-stage hepatocellular carcinoma patients. Cancer Res 2010; 70: 10202-12. https://doi. org/10.1158/0008-5472.CAN-10-2607

[18] UHLEN M, FAGERBERG L, HALLSTROM BM, LINDSKOG C, OKSVOLD P et al. Proteomics. Tissue-based map of the human proteome. Science 2015; 347: 1260419. https:// doi.org/10.1126/science.1260419

[19] YOSHIMATSU M, TOYOKAWA G, HAYAMI S, UNOKI M, TSUNODA T et al. Dysregulation of PRMT1 and PRMT6, Type I arginine methyltransferases, is involved in various types of human cancers. Int J Cancer 2011; 128: 562573. https://doi.org/10.1002/ijc.25366

[20] DERYUGINA EI, QUIGLEY JP. Matrix metalloproteinases and tumor metastasis. Cancer Metastasis Rev 2006; 25: 9-34. https://doi.org/10.1007/s10555-006-7886-9

[21] GUICHARD C, AMADDEO G, IMBEAUD S, LADEIRO $\mathrm{Y}$, PELLETIER $\mathrm{L}$ et al. Integrated analysis of somatic mutations and focal copy-number changes identifies key genes and pathways in hepatocellular carcinoma. Nat Genet 2012; 44: 694-698. https://doi.org/10.1038/ng.2256
[22] ZHANG T, CUI G, YAO YL, GUO Y, WANG QC et al. Inhibition of Nonsmall Cell Lung Cancer Cell Migration by Protein Arginine Methyltransferase 1-small Hairpin RNA Through Inhibiting Epithelial-mesenchymal Transition, Extracellular Matrix Degradation, and Src Phosphorylation In Vitro. Chin Med J (Engl) 2015; 128: 1202-1208. https://doi. org/10.4103/0366-6999.156126

[23] PAPADOKOSTOPOULOU A, MATHIOUDAKI K, SCORILAS A, XYNOPOULOS D, ARDAVANIS A et al. Colon cancer and protein arginine methyltransferase 1 gene expression. Anticancer Res 2009; 29: 1361-1366.

[24] WANG S, TAN X, YANG B, YIN B, YUAN J et al. The role of protein arginine-methyltransferase 1 in gliomagenesis. BMB Rep 2012; 45: 470-475. https://doi.org/10.5483/BMBRep.2012.45.8.022.

[25] MATHIOUDAKI K, SCORILAS A, ARDAVANIS A, LYMBERI P, TSIAMBAS E et al. Clinical evaluation of PRMT1 gene expression in breast cancer. Tumour Biol 2011; 32: 575582. https://doi.org/10.1007/s13277-010-0153-2

[26] YANG J, WEINBERG RA. Epithelial-mesenchymal transition: at the crossroads of development and tumor metastasis. Dev Cell 2008; 14: 818-829. https://doi.org/10.1016/j.devcel.2008.05.009

[27] SAITOH M. Epithelial-mesenchymal transition is regulated at post-transcriptional levels by transforming growth factorbeta signaling during tumor progression. Cancer Sci 2015; 106: 481-488. https://doi.org/10.1111/cas. 12630

[28] ONDER TT, GUPTA PB, MANI SA, YANG J, LANDER ES et al. Loss of E-cadherin promotes metastasis via multiple downstream transcriptional pathways. Cancer Res 2008; 68: 3645-3654. https://doi.org/10.1158/0008-5472.CAN-072938

[29] KATZ LH, LI Y, CHEN JS, MUNOZ NM, MAJUMDAR A et al. Targeting TGF-beta signaling in cancer. Expert Opin Ther Targets 2013; 17: 743-760. https://doi.org/10.1517/147 28222.2013.782287

[30] LIU LC, TSAO TC, HSU SR, WANG HC, TSAI TC et al. EGCG inhibits transforming growth factor-beta-mediated epithelial-to-mesenchymal transition via the inhibition of Smad2 and Erk1/2 signaling pathways in nonsmall cell lung cancer cells. J Agric Food Chem 2012; 60: 9863-9873. https://doi.org/10.1021/jf303690x

[31] CHA B, PARK Y, HWANG BN, KIM SY, JHO EH. Protein Arginine Methyltransferase 1 Methylates Smurf2. Mol Cells 2015; 38: 723-728. https://doi.org/10.14348/molcells. 2015.0113 